\title{
Cost assessment of efficiency losses in hydroelectric plants
}

\author{
J.C. Galvis ${ }^{a}$, A. Padilha-Feltrin ${ }^{\mathrm{a}, *}$, J.M. Yusta Loyo ${ }^{\mathrm{b}}$ \\ a UNESP - State University of São Paulo, Department of Electrical Engineering, Ilha Solteira, SP, 15385-000, Brazil \\ ${ }^{\mathrm{b}}$ UNIZAR - University of Zaragoza, Department of Electrical Engineering, Zaragoza, 50018, Spain
}

\section{A R T I C L E I N F O}

\section{Article history:}

Received 5 July 2010

Received in revised form 6 April 2011

Accepted 16 May 2011

\section{Keywords:}

Ancillary services

Efficiency losses

Hydroelectric generators

Operating reserve

\begin{abstract}
A B S T R A C T
Some important real-time tasks of the independent system operator (ISO) are the monitoring and control of power system events (load deviations and contingencies). These events are usually managed by the ISO using operating reserve ancillary services. These services represent an additional capacity (MW) available in generators and some interruptible loads. Generators must change their operating points in order that this capacity can remain available. These changes might lead to efficiency losses in energy production. In systems with a high percentage of hydroelectric production, hydroelectric plants need to know the impact of ancillary services on their profits. This work therefore analyzes the cost of efficiency losses due to operating reserve availability in hydroelectric generators. A method to calculate this cost component is proposed using a unit commitment dispatch for a single hydroelectric plant. This dispatch is performed without considering the operating reserve availability and is compared with the traditional dispatch, which takes into account the availability of operating reserve. The proposal is used to calculate the cost of efficiency losses on a Brazilian hydroelectric generator. We found that the cost of efficiency losses can be considerable when compared to the incomes of a hydroelectric plant in the short-term market.
\end{abstract}

(c) 2011 Elsevier B.V. All rights reserved.

\section{Introduction}

Operating reserve services are used in frequency control to compensate for load deviations and contingencies. To this end, the independent system operator (ISO) asks some users (generators or interruptible loads) for reserve supplies. Generators supply additional capacity to cover load deviations and contingencies. Interruptible loads provide reserve through a partial or total reduction of the load. The ISO provides operating reserve services through any of the following methods: compulsory provision, bilateral contracts, long- or short-term markets or a combination thereof [1]. Some studies illustrate market mechanisms for reserve pricing [2-5]. On the other hand, other studies show pricing reserve methods without considering a market mechanism [6,7]. Choosing among those alternatives is a challenging task that depends on many factors, including system requirements, existing market structure, regulations and the economy [8]. Regardless of the scheme used, it is important that generators assess the cost of the operating reserve so that this cost can be appropriately budgeted.

In the Brazilian system, $84 \%$ of energy production comes from hydroelectric resources. In this system, the operating reserve supply used for frequency control is compulsory and does not add any

\footnotetext{
* Corresponding author. Tel.: +55 18 37431169; fax: +55 1837431163 .

E-mail addresses: juancgalvis@gmail.com(J.C.Galvis),padilha@dee.feis.unesp.br (A. Padilha-Feltrin), jmyusta@unizar.es (J.M.Y. Loyo).
}

cost for users [9]. Because hydroelectric plants provide most of the reserve, it is important to calculate the cost of reserve availability for this type of producer.

The contribution of this paper is twofold:

- It analyzes the cost of efficiency losses in hydroelectric plant production due to operating reserve availability.

- It proposes a method of assessment that can show network users the value and significance of this cost component.

Moreover, a regulatory entity and the ISO may also be interested in the proposed method. The regulator may use the proposal to evaluate costs and define specific tariffs for operating reserve services. The ISO may take into account this method as an additional criteria in the generation dispatch in order to reduce system operation costs.

The paper is organized as follows. First, Section 2 illustrates the classification and cost components associated with operating reserve. Next, Section 3 describes relevant aspects of the Brazilian market while Section 4 discusses the cost of efficiency losses in the production of hydroelectric plants. Section 5 shows a unit commitment dispatch for a single hydroelectric plant in order to calculate this cost component. In Section 6, the proposal is used to calculate the cost of efficiency losses on a Brazilian hydroelectric generator. Finally, Section 7 provides an outline of research conclusions. 


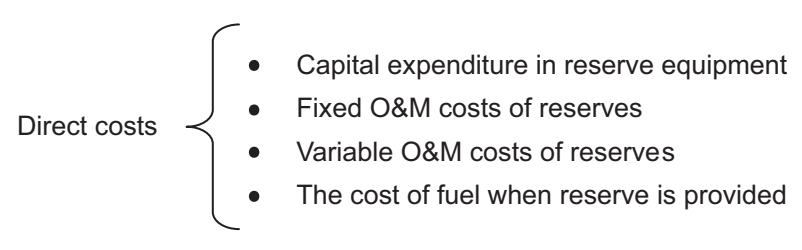

Indirect costs $\left\{\right.$ finantial losses $\begin{cases}\cdot & \text { In the energy market } \\ & \text { (opportunity costs) } \\ & \text { By efficiency losses in } \\ \text { energy production }\end{cases}$

Note: O\&M: Operation and mainteinance

Fig. 1. Operating reserve cost components.

\section{Operating reserve}

\subsection{Classification}

Operating reserve constitutes part of the criteria for system adequacy. It includes spinning and non-spinning reserve [10]. Operating reserve is also classified (from the fastest to the slowest) as primary, secondary and tertiary control reserves [11]. Primary, secondary and part of tertiary reserve are spinning reserves. The remaining part of tertiary reserve may be classified as non-spinning reserve. For hydroelectric plants in the Brazilian system, operating reserve is comprised of the sum of three components: primary, secondary and spinning tertiary reserves. This reserve represents any additional capacity available in the generator units [12].

\subsection{Cost components}

The main cost components associated with operating reserve in hydroelectric generators are illustrated in Fig. 1. Direct cost components of operating reserves are similar to energy production cost components. They are usually bundled, since generator units provide reserve and energy simultaneously. For hydroelectric plants, fuel (water) and O\&M costs are considered small. However, reserve supply can still indirectly impact the generator's profit. Fig. 1 illustrates two examples: opportunity costs and the cost of efficiency losses.

When the generator has a reserve constraint that limits sales in the energy market, and the sales limitation causes a loss of profit, the generator incurs in an opportunity cost [13]. On the other hand, reserve constraints can also cause efficiency losses in energy production and, consequently, a loss of profit. This occurs because a more efficient generator uses the same amount of water as a less efficient generator, but produces more than a less efficient generator does. In this paper, we focus on calculating the cost associated with efficiency losses in energy production.

\section{Brazilian market framework}

\subsection{Energy market}

Currently, the Brazilian electrical sector is comprised of public, private and semi-private companies. These companies trade energy in two contracting environments: the regulated contracting environment (RCE) and the free contracting environment (FCE). Most of the energy produced is negotiated in the RCE, which is comprised of public long-term auctions with five, three and one year in advance of real-time operation. In these auctions, sellers (generator companies) bid price/quantity offers of energy until the total demand requirements of participating distribution companies are met. After that, the market regulator creates financial contracts between winner generators and distribution companies. The price of these contracts is the marginal price of the corresponding auction. In the FCE, on the other hand, sellers (generator companies) and buyers (retailers and free consumers) agree to bilateral contracts with unique prices, quantities and durations.

Due to its geographical extent, the Brazilian market is divided into four regions (north, northeast, southeast/central-west and south). It is usual to find drought in some regions, while other regions are experiencing a period of rainfall. Because of the high amount of hydroelectric production, the optimal management of water is a priority. Therefore, the ISO solves the hydrothermal dispatch problem in order to set up energy planning policies. This dispatch is based on a chain of computational models with different time scales from five years until one week in advance of real-time operation [14].

The day-ahead dispatch is scheduled according to the energy planning policies. Hydroelectric plants are scheduled to meet weekly production targets, while thermal plants are scheduled using the minimum production cost criteria. The computational model with the shortest period (a week) gives the marginal energy price for one week. This price is used to settle discrepancies between real and contracted generation. For that reason, this price is called the settlement price for differences (SPD) [15]. This price differs by region because of interconnection constraints.

\subsection{Energy reallocation mechanism}

Hydroelectric plants participate in a process known as energy reallocation mechanism (ERM) before settling their energy imbalances at the SPD. This process collects the energy production and then redistributes that energy among these plants in order to reduce differences between real and contracted energy [16]. The price of energy in the ERM is regulated and kept constant throughout the year. This price is lower than the SPD (roughly $10 \%$ of the average SPD).

In order to formulate the settlement process of a hydroelectric plant, we have defined the following variables:

$E_{\mathrm{p}}$ : plant's produced energy.

$E_{\mathrm{r}}$ : plant's reallocated energy.

$E_{\mathrm{c}}$ : plant's contracted energy.

$c_{\mathrm{p}}$ : unitary cost for plant's produced energy.

$\pi_{\text {ERM }}$ : tariff of the ERM for plant's reallocated energy.

$\pi_{\mathrm{c}}$ : price of plant's contracted energy.

$\pi_{\mathrm{SPD}}$ : price for energy imbalances (SPD).

Considering these variables, there are two possible situations:

a. $E_{\mathrm{p}}>E_{\mathrm{c}}$ : in this case, the plant contributes with $E_{\mathrm{r}}$ to the ERM in order to reduce the difference (positive) with respect to its contracted energy. This contribution is priced at the ERM tariff, $\pi_{\mathrm{ERM}}$, and it constitutes an income for the generator.

b. $E_{\mathrm{p}}<E_{\mathrm{c}}$ : in this case, the plant receives $E_{\mathrm{r}}$ from the ERM in order to reduce the difference (negative) with respect to its contracted energy. In this situation, the generator pays a price $\pi_{\mathrm{ERM}}$ for $E_{\mathrm{r}}$. This case is illustrated in Fig. 2. It can be observed in that figure, that without $E_{\mathrm{r}}$, the difference of energy would be higher.

Therefore, a hydroelectric generator can contribute to or receive energy from this mechanism. The ERM can be seen as both a balancing mechanism and a cooperative process that protects generators against risks caused by hydrological uncertainties and SPD variations.

From Fig. 2, if $E_{\mathrm{p}} \pm E_{\mathrm{r}}>E_{\mathrm{c}}$, the difference of energy is positive and the generator sells that difference at $\pi_{\mathrm{SPD}}$. Otherwise, 


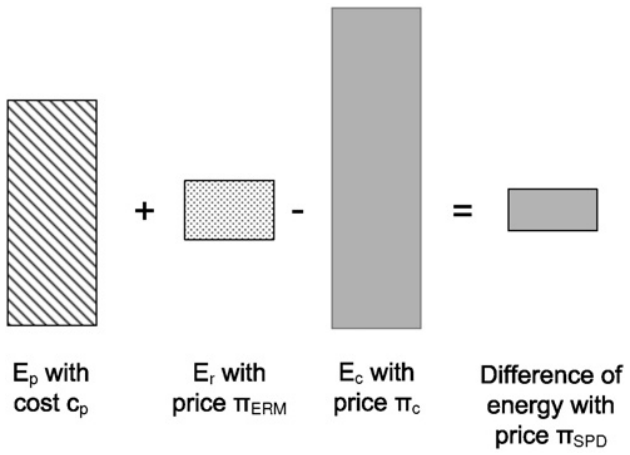

Fig. 2. Energy components in the settlement process.

if $E_{\mathrm{p}} \pm E_{\mathrm{r}}<E_{\mathrm{c}}$, the generator buys the difference at $\pi_{\mathrm{SPD}}$. Generator's energy imbalances and reallocations are settled by the market administrator. However, contracts of energy are settled between the compromised parts.

A hydroelectric plant may have different contracts at different prices. Without loss of generality, we have assumed an equivalent price $\pi_{c}$ for all the contracted energy. The profit of a hydroelectric generator can be determined as follows:

Profit $=\pi_{\mathrm{c}} \times E_{\mathrm{c}}+\pi_{\mathrm{SPD}} \times\left(E_{\mathrm{p}}+E_{\mathrm{r}}-E_{\mathrm{c}}\right)-c_{\mathrm{p}} \times E_{\mathrm{p}}-\pi_{\mathrm{ERM}} \times E_{\mathrm{r}}$

In (1), $E_{\mathrm{c}}$ and $E_{\mathrm{p}}$ are always positive quantities, while $E_{\mathrm{r}}$ is positive when the plant is buying energy from the ERM and negative when it is selling energy to the ERM.

\subsection{Ancillary services}

In the Brazilian system, there are several defined ancillary services: primary and secondary frequency control with the corresponding reserves; quick start reserves; reactive support; black start service and the special protection system. With the exception of primary frequency control, bilateral contract arrangements are made between generators and the ISO for all services. These services are compulsory and there is no price negotiation except a cost compensation that is paid through transmission charges. In most cases, this compensation covers investment and O\&M costs. Only reactive supply provided by synchronous condensers is paid through regulated tariff [9].

\section{Cost of efficiency losses in hydroelectric production}

This section presents a formulation to calculate the cost of efficiency losses in hydroelectric plants. We assess this cost in terms of the financial loss that occurs when the generator operates at a less efficient point. This financial loss can be calculated as the difference between the company's profit when energy is produced at a more efficient point and the company's profit when energy is produced at a less efficient point. A more efficient point, in this case, is obtained from a dispatch without reserve constraints. On the other hand, a less efficient point is obtained from a traditional dispatch with reserve constraints. For convenience, the analysis below represents every cost in (\$) with an upper-cased " $C$ ", while every cost per MWh $(\$ / M W h)$ is represented with a lower-cased " $c$ ". The cost of efficiency losses, $C^{\text {loss }}$, is calculated as follows:

$C^{\text {loss }}=$ Profit $^{\text {ef }}-$ Profit

being

Profit $^{\mathrm{ef}}=\pi_{\mathrm{c}} \times E_{\mathrm{c}}+\pi_{\mathrm{SPD}}^{\mathrm{ef}} \times\left(E_{\mathrm{p}}^{\mathrm{ef}}+E_{\mathrm{r}}^{\mathrm{ef}}-E_{\mathrm{c}}\right)-c_{\mathrm{p}}^{\mathrm{ef}} \times E_{\mathrm{p}}^{\mathrm{ef}}-\pi_{\mathrm{ERM}} \times E_{\mathrm{r}}^{\mathrm{ef}}$ wherein the superscript "ef" represents the efficient scenario. In the following analysis we made some assumptions:

a. Costs are analyzed considering the variation of a plant's produced energy without accounting for simultaneous variations in many plants;

b. When the efficiency of the plant is improved, variation in the SPD may occur; variations would be due to the fact that more hydro generation is available and the system operator would therefore decide to make a new dispatch. For simplicity, we assume that the SPD in the efficient scenario is the same as in the traditional scenario (in which the SPD is known). Given this assumption, the proposal does not need additional information, does not involve an energy planning simulation and considers only one price (the real SPD). Therefore:

$\pi_{\mathrm{SPD}}^{\mathrm{ef}}=\pi_{\mathrm{SPD}}$

c. The production costs per MWh of a generator operating at a more efficient point are assumed to be lower than the production costs of a generator operating at a less efficient point. Therefore:

$c_{\mathrm{p}}^{\mathrm{ef}}=c_{\mathrm{p}}-\Delta c_{\mathrm{p}}$

being $\Delta c_{\mathrm{p}}>0$, the variation of the production cost per MWh.

d. It is assumed that produced energy at a more efficient point $E_{\mathrm{p}}^{\mathrm{ef}}$ must be greater than produced energy at a less efficient point $E_{\mathrm{p}}$; therefore:

$E_{\mathrm{p}}^{\mathrm{ef}}=E_{\mathrm{p}}+\Delta E_{\mathrm{p}}$

being $\Delta E_{\mathrm{p}}>0$ the variation of the produced energy.

e. Since it was assumed that there is more energy production in the efficient scenario (Eq. (6)), the hydroelectric plant, depending on its contracted energy, would need less energy from the ERM or would contribute with more energy to the ERM when compared with the traditional scenario. Thus:

$E_{\mathrm{r}}^{\mathrm{ef}}=E_{\mathrm{r}}-\Delta E_{\mathrm{r}}$

Eq. (7) shows the case in which the plant receives less energy from the ERM in the efficient scenario. If the plant is selling energy to the ERM, variables $E_{\mathrm{r}}^{\mathrm{ef}}$ and $E_{\mathrm{r}}$ are negative. In both cases, $\Delta E_{\mathrm{r}}$ is positive and constitutes a portion of $\Delta E_{\mathrm{p}}$.

By replacing (1) and (3)-(7) in (2):

$C^{\text {loss }}=\pi_{\mathrm{SPD}} \times\left(\Delta E_{\mathrm{p}}-\Delta E_{\mathrm{r}}\right)+\pi_{\mathrm{ERM}} \times \Delta E_{\mathrm{r}}-c_{\mathrm{p}} \times \Delta E_{\mathrm{p}}+\Delta c_{\mathrm{p}} \times E_{\mathrm{p}}^{\mathrm{ef}}$.

In (8), four components can be identified:

- The difference between variations of produced and reallocated energy assessed at the SPD;

- The variation of the reallocated energy assessed at the tariff of the ERM;

- The variation of the produced energy assessed by the production costs per MWh;

- The produced energy at a more efficient point assessed by the variation of the production cost per MWh.

If the production cost per MWh is constant, then $\Delta c_{\mathrm{p}} \rightarrow 0$ and (8) can be notated as follows:

$C^{\text {loss }}=\left(\pi_{\mathrm{SPD}}-c_{\mathrm{p}}\right) \times \Delta E_{\mathrm{p}}-\left(\pi_{\mathrm{SPD}}-\pi_{\mathrm{ERM}}\right) \times \Delta E_{\mathrm{r}}$.

Produced energy variations cannot be forecasted, because they depend on real-time operations. Thus, $\Delta E_{\mathrm{p}}$ will be approximated by the scheduled energy variation $\Delta E_{s}$. This variation can be calculated using a unit commitment dispatch for a single hydroelectric 


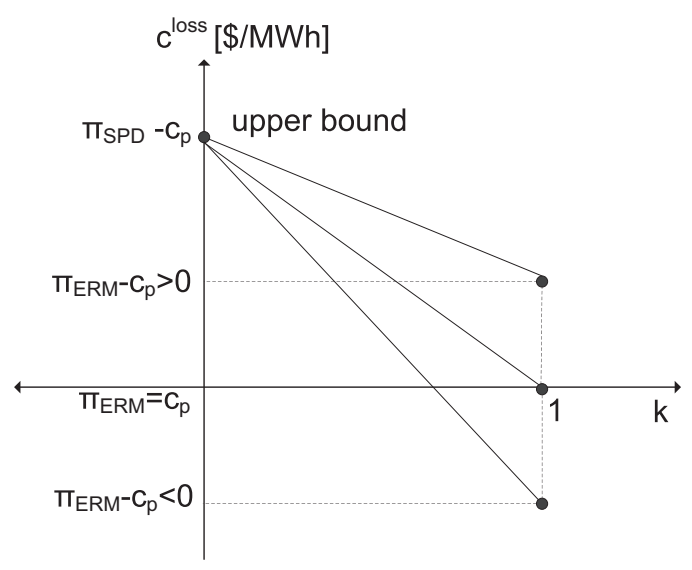

Fig. 3. Possible values for the cost of efficiency losses.

generator, which will be described later in Section 5. The cost of efficiency losses is thus determined by (10).

$C^{\text {loss }}=\left(\pi_{\mathrm{SPD}}-c_{\mathrm{p}}\right) \times \Delta E_{\mathrm{S}}-\left(\pi_{\mathrm{SPD}}-\pi_{\mathrm{ERM}}\right) \times \Delta E_{\mathrm{r}}$.

Eq. (10) shows that if $\Delta E_{\mathrm{r}}$ is equal to zero then no ERM is considered. Therefore, the cost of efficiency losses is equal to the profit of the generator in the short-term market when an extra amount of energy, $\Delta E_{\mathrm{s}}$, is produced.

Since $\Delta E_{\mathrm{r}}$ constitutes a portion of $\Delta E_{\mathrm{s}}$, we can relate these variables as $\Delta E_{\mathrm{r}}=k \times \Delta E_{\mathrm{s}}$ with $0 \leq k \leq 1$. Thus:

$$
\begin{aligned}
& C^{\text {loss }}=\left(\pi_{\mathrm{SPD}}-c_{\mathrm{p}}\right) \times \Delta E_{\mathrm{S}}-\left(\pi_{\mathrm{SPD}}-\pi_{\mathrm{ERM}}\right) \times k \times \Delta E_{\mathrm{S}} . \\
& \frac{C^{\text {loss }}}{\Delta E_{\mathrm{S}}}=\pi_{\mathrm{SPD}} \times(1-k)-c_{\mathrm{p}}+k \times \pi_{\mathrm{ERM}} \\
& c^{\text {loss }}=\pi_{\mathrm{SPD}} \times(1-k)-c_{\mathrm{p}}+k \times \pi_{\mathrm{ERM}}
\end{aligned}
$$

The cost of efficiency losses per MWh (13) can be depicted in function of $k$ as illustrated in Fig. 3. The production cost $c_{\mathrm{p}}$ is lower than $\pi_{\text {SPD }}$ because the SPD is usually determined by a thermal plant. Additionally, in Brazil the ERM tariff is used to cover the operational and maintenance costs of hydroelectric plants [17]. In the case of older plants, it can be assumed that $c_{\mathrm{p}} \cong \pi_{\mathrm{ERM}}$, provided that the investment cost component has been recovered. If these plants are more efficient, then it could happen that $c_{\mathrm{p}}<\pi_{\mathrm{ERM}}$. In the case of new plants, it is expected that $c_{\mathrm{p}}>\pi_{\mathrm{ERM}}$. Fig. 3 shows that $c^{\text {loss }}$ can be zero or even negative. In the latter case, the generator benefits from efficiency variations.

\section{Unit commitment dispatch for a single hydroelectric plant}

According to Section 4, efficiency losses in production can be calculated comparing two scenarios: an efficient scenario without reserve constraints, and a traditional scenario with reserve constraints. This section describes a unit commitment dispatch model for a single hydroelectric generator. This dispatch calculates the production levels in the efficient scenario.

In the unit commitment dispatch problem, the plant must determine the production level of its units during each period in order to minimize the operational costs.

The problem's model initiates with a formula that determines the generation level of a generator unit. This formula is known as the production function (14).

$p=k_{\text {eq }} \times \eta_{\text {eq }} \times q \times h_{l}$

wherein $k_{\text {eq }}$ is the equivalent constant of the gravitational acceleration and the specific weight of water $\left(k_{\mathrm{eq}}=9.81 \times 10^{-3}\left[\mathrm{MW} /\left(\left(\mathrm{m}^{3} / \mathrm{s}\right) \mathrm{m}\right)\right]\right), \quad \eta_{\mathrm{eq}}$ is the equivalent efficiency of the turbine-generator set in (\%), $q$ is the water discharge in $\left(\mathrm{m}^{3} / \mathrm{s}\right), h_{l}$ is the net water head of the plant in $(\mathrm{m})$ and $p$ is the generated power in (MW). Net water head and equivalent efficiency are described by non-linear functions. Net water head depends on turbine water discharge, penstock losses, spillage and storage of reservoir while equivalent efficiency depends on water discharge and net water head. However, if net water head is known, the production function can be approximated by a polynomial with water discharge as an independent variable. For most hydroelectric plants in the Brazilian system, Finardi and da Silva [18] demonstrate that a better approximation for the production function is a polynomial of degree 7 . Thus:

$p(q)=a_{1} q^{7}+a_{2} q^{6}+a_{3} q^{5}+a_{4} q^{4}+a_{5} q^{3}+a_{6} q^{2}+a_{7} q+a_{8}$

Coefficients $a_{i}$ depend on the operation point and are fitted using data from the unit's Hill diagram. This diagram describes the relationship among equivalent efficiency, water discharge, net water head and power production.

On the other hand, an optimal dispatch modifies production levels and may cause constant switching among the plant's units, in order to operate them at a more efficient point. The objective of the dispatch problem, therefore, focuses on the minimization of start/stop costs of units and the maximization of incomes caused by the energy produced during each period (16).

$\operatorname{Min} F=C^{p / p} \times \sum_{t=1}^{T}\left|n_{t}-n_{t-1}\right|-\sum_{t=1}^{T} \pi_{t} \times p_{t} \times n_{t} \times h_{t}$

wherein $C^{p / p}$ is the start/stop cost of generator units, $T$ is the number of periods, $n_{t}$ is the number of generator units operating at time $t$, $\pi_{t}$ is the price of the produced energy at time $t$ and $h_{t}$ is the duration of period $t$.

If the value of the objective function is $F^{*}$ in the efficient scenario and $\hat{F}$ in the traditional scenario (with reserve constraints), the cost of efficiency losses can be calculated as described below.

$$
\begin{gathered}
C^{\text {loss }}=F^{*}-\hat{F}=C^{p / p} \times \sum_{t=1}^{T}\left|n_{t}^{*}-n_{t-1}^{*}\right|-\left|\hat{n}_{t}-\hat{n}_{t-1}\right| \\
-\sum_{t=1}^{T} \hat{\pi}_{t} \times\left(p_{t}^{*} \times n_{t}^{*}-\hat{p}_{t} \times \hat{n}_{t}\right) \times h_{t}
\end{gathered}
$$

Variables with belong to the traditional dispatch while variables with * belong to the efficient scenario. Scheduled production $\hat{p}_{t}$ in the traditional dispatch are simulated data before the operation and historical data after the operation. Either simulated or historical data, variables with * are supposed to be given in the proposed methodology. On the other hand, variables with * in the efficient scenario can only be obtained by simulation as a result of an optimization process.

The product $p_{t} \times n_{t}$ represents the total production of the plant in MW for period $t$, which is supposed to be of a duration $h_{t}$ of one hour:

$$
C^{\text {loss }}=C^{p / p} \times \sum_{t=1}^{T}\left|n_{t}^{*}-n_{t-1}^{*}\right|-\left|\hat{n}_{t}-\hat{n}_{t-1}\right|-\sum_{t=1}^{T} \hat{\pi}_{t} \times \Delta E_{\mathrm{st}}
$$

The first term in Eq. (18) represents a variation in production costs due to start/stop of units, while the second term represents the cost of the variation in produced energy. According to Eqs. (12) and (13), $C_{t}^{\text {loss }}=c_{t}^{\text {loss }} \times \Delta E_{\text {st }}$. Since those equations assume no variation in production costs, the variation in produced energy can be priced as $\hat{\pi}_{t}=c_{t}^{\text {loss }}$ in Eq. (18). Therefore Eq. (18) can be 


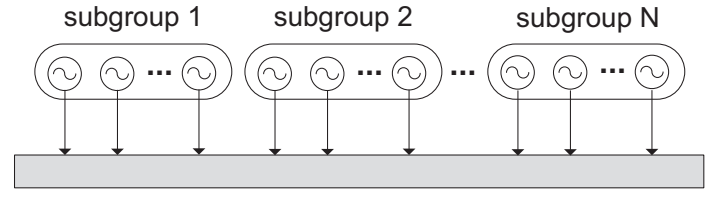

Fig. 4. Subgroups of units inside the plant.

Table 1

Subgroups of generators.

\begin{tabular}{ll}
\hline$g r_{1}$ & $G_{1}-G_{4}$ \\
$g r_{2}$ & $G_{5}-G_{10}, G_{12}, G_{14}, G_{15}, G_{17}, G_{18}$ \\
$g r_{3}$ & $G_{11}, G_{13}, G_{16}, G_{19}, G_{20}$ \\
\hline
\end{tabular}

seen as similar to Eq. (12); however, the former includes the variation in production costs due to start/stop of units. According to Fig. 3, the maximum price of the variation in produced energy is $\hat{\pi}_{t}=c^{\text {loss }}=\pi_{\mathrm{SPD}}-c_{\mathrm{p}}$. This value occurs when $k=0$ - that is, when no portion of the variation in scheduled energy is reallocated in the ERM.

Considering a hydroelectric plant with a target discharge $Q_{t}$ in each period, the unit commitment dispatch can be expressed as the following nonlinear mixed integer problem (Model-1):

Min $F$

s.a.

$p_{t}\left(q_{t}\right)=a_{1 t} q_{t}^{7}+a_{2 t} q_{t}^{6}+a_{3 t} q_{t}^{5}+a_{4 t} q_{t}^{4}+a_{5 t} q_{t}^{3}+a_{6 t} q_{t}^{2}+a_{7 t} q_{t}+a_{8 t}$

$n_{t} \times q_{t}=Q_{t} \quad \forall t$

$q_{t-\min } \leq q_{t} \leq q_{t-\max }$

$n_{t-\min } \leq n_{t} \leq n_{t-\max }$

In practice, all generator units within a plant are not necessarily the same. The variations in generators can be modeled taking into account some subgroups. A subgroup is a set of generator units with the same characteristics (Fig. 4).

In this case, the optimal dispatch model considering $N$ subgroups of units inside the plant can be represented by Eqs. (24)-(28) (Model-2).

$\operatorname{Min} C^{p / p} \times \sum_{t=1}^{T} \sum_{j=1}^{N}\left|n_{t j}-n_{t-1 j}\right|-\sum_{t=1}^{T} \hat{\pi}_{t} \times \sum_{j=1}^{N} p_{t j} \times n_{t j}$

s.a.

$p_{t j}\left(q_{t j}\right)=a_{1 t j} q_{t j}^{7}+a_{2 t j} q_{t j}^{6}+a_{3 t j} q_{t j}^{5}+a_{4 t j} q_{t j}^{4}+a_{5 t j} q_{t j}^{3}$

$+a_{6 t j} q_{t j}^{2}+a_{7 t j} q_{t j}+a_{8 t j}$

$\sum_{j=1}^{N} n_{t j} \times q_{t j}=Q_{t} \quad \forall t$

$q_{t j-\min } \leq q_{t j} \leq q_{t j-\max }$

$n_{t j-\min } \leq n_{t j} \leq n_{t j-\max }$

Model-2 is also a nonlinear mixed integer problem with a solution space greater than the solution space of Model-1.

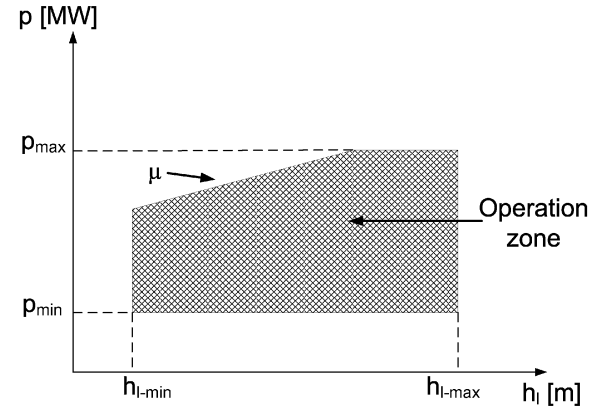

Fig. 5. Operation zone of a generator unit.

Table 2

Subgroup characteristics.

\begin{tabular}{lccll}
\hline & $n_{k-\max }$ & $p_{\min }[\mathrm{MW}]$ & $p_{\max }[\mathrm{MW}]$ & $\mu[\mathrm{MW} / \mathrm{m}]$ \\
\hline$g r_{1}$ & 4 & 120 & $176^{\mathrm{a}}$ & 3.76 \\
$g r_{2}$ & 11 & 90 & $170^{\mathrm{b}}$ & 3.41 \\
$g r_{3}$ & 5 & 90 & $174^{\mathrm{c}}$ & 3.19 \\
\hline
\end{tabular}

Maximum power for $h_{l}>46 \mathrm{~m}$.

Maximum power for $h_{l}>46 \mathrm{~m}$.

c Maximum power for $h_{l}>47.6 \mathrm{~m}$.

\section{Numerical results}

This section shows the results obtained for the cost of efficiency losses occurring at a Brazilian hydroelectric plant with 20 generator units. After grouping generator units with the same characteristics, the subgroups were classified as indicated in Table 1. Each subgroup has a specific operation zone and a corresponding Hill diagram. The operation zone is defined by power limits that are function of the net water head (Fig. 5). Table 2 shows the parameters of the operation zone for each subgroup. The corresponding Hill diagram was used to calculate the fitting of the production functions. Fig. 6 illustrates the fitting curves of subgroup 1 . Water discharge limits in (22) and (27) can be calculated from Table 2 and Fig. 6.

Calculations for efficiency losses were performed for each day from recorded data in 2006. Table 3 illustrates the scheduled generation of each unit, the target water discharge and the net water head for six hours of that year. This table shows that the maximum number of units in each subgroup depends upon the operating availability of each generator unit. For example, the number of

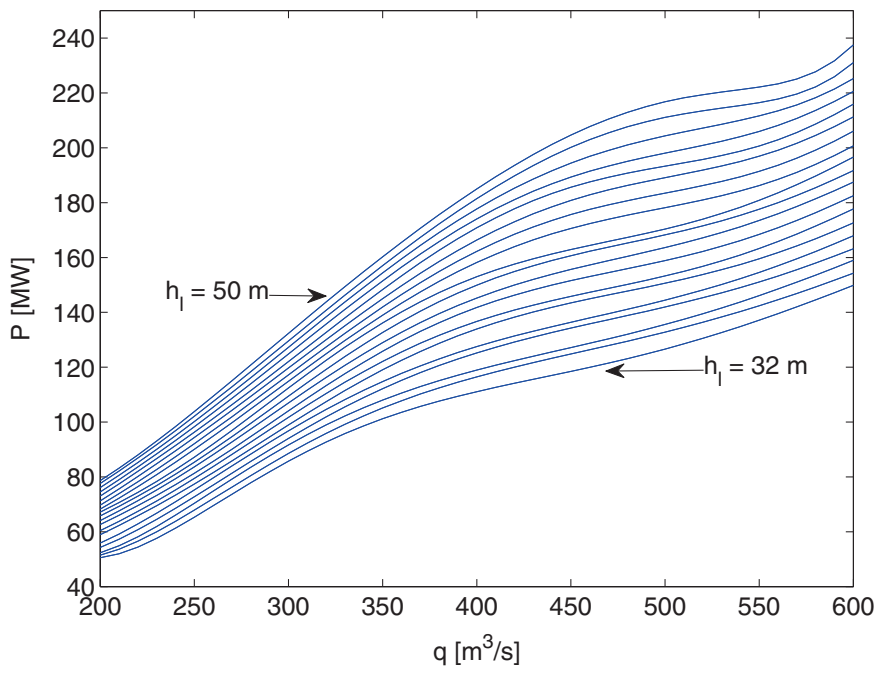

Fig. 6. Hydroelectric production curves for subgroup 1. 
Table 3

Generation scheduling [MW].

\begin{tabular}{|c|c|c|c|c|c|c|c|c|c|c|c|}
\hline Hour & $G_{1}$ & $G_{2}$ & $G_{3}$ & $G_{4}$ & $G_{5}$ & $G_{6}$ & $G_{7}$ & $G_{8}$ & $G_{9}$ & $G_{10}$ & $\mathrm{Q}\left(\mathrm{m}^{3} / \mathrm{s}\right)$ \\
\hline 01 & 125 & 124 & $\mathrm{CO}$ & 123 & 116 & 116 & 116 & 116 & 115 & 116 & 4778 \\
\hline 02 & 127 & 127 & $\mathrm{CO}$ & 128 & 119 & $\mathrm{CO}$ & 5 & 6 & 119 & 117 & 3920 \\
\hline 03 & 125 & 125 & $\mathrm{CO}$ & 125 & 100 & $\mathrm{CO}$ & $\mathrm{CO}$ & $\mathrm{CO}$ & 98 & 99 & 3359 \\
\hline 04 & 132 & 132 & $\mathrm{CO}$ & 132 & 132 & $\mathrm{CO}$ & $\mathrm{CO}$ & $\mathrm{CO}$ & 134 & 138 & 3968 \\
\hline 05 & 123 & 122 & $\mathrm{CO}$ & 122 & 102 & $\mathrm{CO}$ & $\mathrm{CO}$ & $\mathrm{CO}$ & 103 & 104 & 3402 \\
\hline 06 & 142 & 140 & $\mathrm{CO}$ & 140 & 117 & $\mathrm{CO}$ & $\mathrm{CO}$ & $\mathrm{CO}$ & 138 & 141 & 4111 \\
\hline Hour & $G_{11}$ & $G_{12}$ & $G_{13}$ & $G_{14}$ & $G_{15}$ & $G_{16}$ & $G_{17}$ & $G_{18}$ & $G_{19}$ & $G_{20}$ & $h_{l}(\mathrm{~m})$ \\
\hline 01 & 132 & 117 & $\mathrm{CO}$ & $\mathrm{CO}$ & 117 & 116 & 117 & 117 & $\mathrm{AIO}$ & 119 & 47 \\
\hline 02 & 132 & 121 & $\mathrm{CO}$ & $\mathrm{CO}$ & 19 & 120 & 120 & 118 & $\mathrm{AIO}$ & 120 & 47 \\
\hline 03 & 132 & 101 & $\mathrm{CO}$ & $\mathrm{CO}$ & $\mathrm{CO}$ & 99 & 101 & 101 & AIO & 101 & 47 \\
\hline 04 & 132 & 133 & $\mathrm{CO}$ & $\mathrm{CO}$ & $\mathrm{CO}$ & 133 & 134 & 136 & AIO & 136 & 47 \\
\hline 05 & 131 & 104 & $\mathrm{CO}$ & $\mathrm{CO}$ & $\mathrm{CO}$ & 103 & 104 & 105 & $\mathrm{AIO}$ & 105 & 47 \\
\hline 06 & 145 & 132 & $\mathrm{CO}$ & $\mathrm{CO}$ & $\mathrm{CO}$ & 143 & 143 & 143 & $\mathrm{AIO}$ & 144 & 47 \\
\hline
\end{tabular}

CO: operating convenience; AIO: machine for maintenance.

0-79MVA: restricted operating zone; 80-124MVA: admissible operating zone. 125-176MVA: optimal operating zone.

machines available during the 5 th hour is 3 of subgroup 1, 6 of subgroup 2, and 3 of subgroup 3. Units can be unavailable for any of the following reasons: operating convenience, synchronous mode operation or maintenance. The upper and lower boundary of constraints (23) and (28) thus vary in function of unit availability in each period.

Water discharge limits (Eqs. (22) and (27)) can also vary in the function of time, because they are associated with generation limits. Generation limits, in turn, are a function of the water head. However, the influence of water head variations on the results was negligible. This occurred because the reservoir level remained between 45 and $47 \mathrm{~m}$ throughout the year, due to the operating policy of the plant.

For each day, the initial number of operating units is equal to the units scheduled for the last hour of the previous day.

Start/stop costs were assumed to be 3.0 US \$/MW based on Nilsson and Sjelvgren's findings [19]. The unitary production cost was assumed to be equal to the ERM tariff. Therefore, the maximum price of energy variations is $\hat{\pi}_{t}=c_{t}^{\text {loss }}=\pi_{\mathrm{SPD}}-\pi_{\mathrm{ERM}}$, according to Fig. 3. Values for $\pi_{\text {SPD }}$ in the southeast/central-west region in 2006 were considered ${ }^{1}$. These values vary for each week and for each load block during the year. Minimum and maximum prices in the southeast/central-west market were 9.3 US \$/MWh and 73.2 US $\$ / M W h$ respectively. Thus, the value of $\hat{\pi}_{t}$ varies as a function of time. On the other hand, the ERM price remains constant during the year, with a value of 4 US \$/MWh in 2006, in the Brazilian system.

Another aspect considered is spillage in the reservoir. During the hours the plant spills water, the value of $\hat{\pi}_{t}$ is considered to be zero. The value is considered so because there is no need to maintain a specific water discharge in these cases; the production at a more efficient point is irrelevant.

Due to its nonlinear characteristic, the solution of the problem depends on an initial feasible solution. In this work, the initial solution for Models 1 and 2 was the solution of the traditional scenario. Additionally, the algorithm presented in [20] was used to calculate, for each period, the minimum and maximum number of units in constraints (23) and (28).

In the proposed method, the model is solved for a one-day horizon using the commercial solver DICOPT on the GAMS interface.

Fig. 7 illustrates the upper bound of the daily cost of efficiency losses for Models 1 and 2. The figure indicates that this cost presents

\footnotetext{
${ }^{1}$ For space reasons, these data are not presented but are available on line: http://www.ccee.org.br/.
}

high volatility, due to variations in the operating point of each scheduled period. The cost can be zero when there is spilling and it is unnecessary to switch additional units on or off during the day. It can also be observed that the cost of efficiency losses may reach values up to US $\$ 157,730$ in one day.

As illustrated in Fig. 8, the solution time in a computer with an Intel Centrino duo processor ( $1.6 \mathrm{GHz}$ and $0.99 \mathrm{MB}$ of RAM), was $4.03 \mathrm{~h}$ for Model-1, and $4.76 \mathrm{~h}$ for Model-2. In this example, the three subgroups have 4,5 and 11 generator units, respectively. Therefore, each day can have up to $(4 \times 5 \times 11)^{24}=220^{24}$ possible integer solutions. For that reason, the solution time was considerable.

The results are not guaranteed to be global optimal solutions. In fact, they can only be local optimal solutions or feasible integer solutions. However, these results were, in most cases, more efficient than the dispatch with reserve constraints made by the generator agent during the year in question.

The accumulated cost of efficiency losses for the year under analysis was 18.8 million dollars using Model-1, and 27.2 million dollars using Model-2. Costs in Model-2 are higher because the model accounts for differences among subgroups, making it a more efficient dispatch.

For this plant, the annual settlement in 2006 was 33.2 and 41.8 million dollars in the ERM and the short-term market, respectively. According to the results, the upper bound of the cost of efficiency

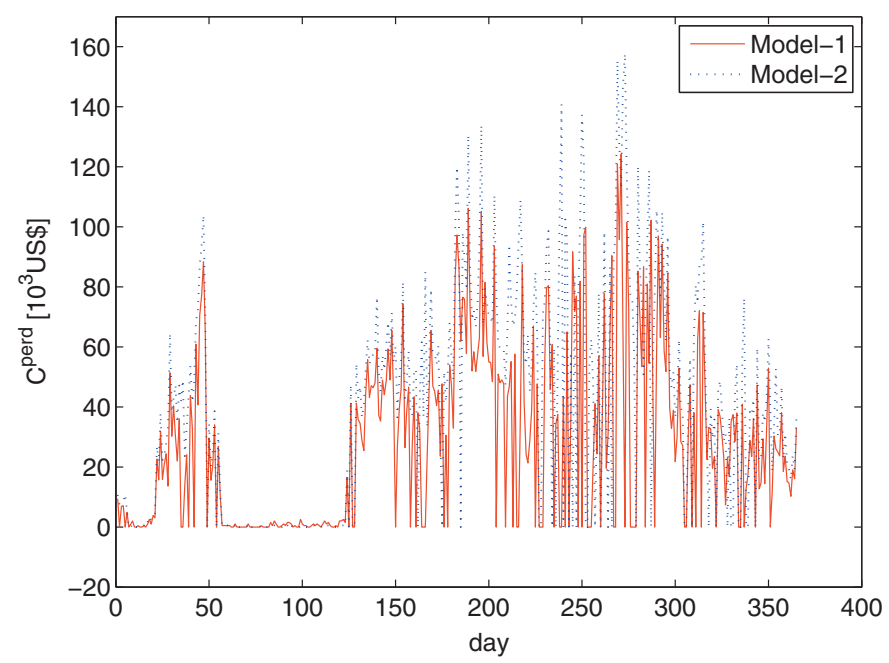

Fig. 7. Daily cost of efficiency losses. 


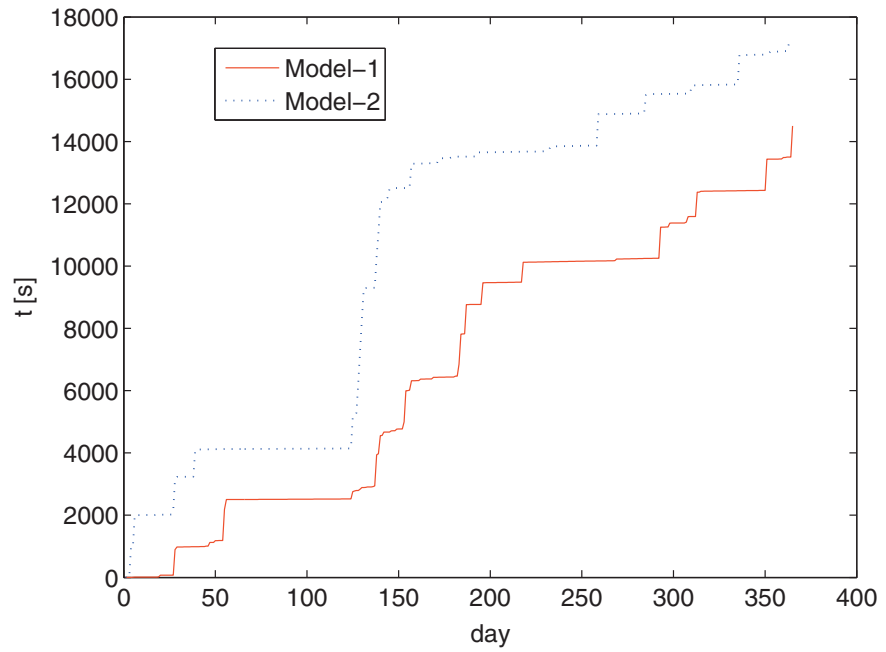

Fig. 8. Accumulated solution time.

losses was between $56 \%$ and $82 \%$ of the generator payments in the ERM, and between $45 \%$ and $65 \%$ of the generator payments in the short term market. Costs calculated under the proposed method are high because of the assumption of non ERM and the large reserve capacity of this plant. Under realistic conditions, these costs depend on the percentage of the variation in the scheduled energy that is reallocated $(k)$ as indicated in Fig. 3. The existence of the ERM reduces the price of the efficiency losses until certain point in the interval $k \in[0,1]$. However, the method does not calculate this point exactly, since reallocated energy is based on real generation and this energy is unknown in the efficient scenario. Therefore, in the Brazilian case, reallocated energy affects the cost of efficiency losses. If the generator operates at a more efficient point, a portion of the extra energy it produces could be reallocated if there is no reserve availability, thus reducing the cost of efficiency losses. In the absence of the ERM, the generator would receive the annual value indicated above, but would not benefit from the ERM.

\section{Conclusions}

This work analyzes the cost of efficiency losses of hydraulic generators and presents a method to assess these losses. The cost assessment was made in terms of the financial loss that occurs when a generator operates at a less efficient point, due to reserve availability. The efficiency loss was calculated by comparing a traditional dispatch that considers reserve constraints to a more efficient dispatch that does not consider reserve constraints. Several aspects were taken into account in this analysis, including: technical differences among units inside the plant, spilling periods throughout the year, the fitting of the production functions in several operating conditions of the plant and the variation of the operational limits in terms of units availability. Results show that the cost of efficiency losses is high due to the assumption of non ERM and the large reserve capacity of this plant. Under realistic conditions, these costs are reduced by the percentage of the variation in reallocated energy. The proposed method does not calculate this variation exactly, since reallocated energy is based on real generation and is unknown in the assumed efficient scenario. Thus, the results illustrated above can be seen as extreme values which show how important could be the assessment of this cost component. Although the ERM is only used in the Brazilian system, the proposed method can be extended to any hydraulic generator when there is no reallocated energy. This cost analysis can help agents and regulators to assess the cost of maintaining an operating reserve.

\section{Acknowledgements}

This project was firstly financed by the Brazilian Federal Agency for the Improvement of Higher Education (CAPES) and later by the National Council for Scientific and Technological Development (CNPq) - process number 152916/2010-5. The authors also thank the São Paulo Energetic Company (CESP) for the provided data.

\section{Appendix A. List of symbols} Profit profit of the plant $(\$)$

$C^{\text {loss }} \quad$ cost of efficiency losses $(\$)$

$c^{\text {loss }} \quad$ unitary cost of efficiency losses $(\$ / \mathrm{MWh})$

$C^{p / p} \quad$ start/stop costs of each unit inside the plant $(\$)$

$c_{\mathrm{p}} \quad$ unitary cost for plant's produced energy $(\$ / \mathrm{MWh})$

$\pi \quad$ price of plant's produced energy $(\$ / M W h)$

$\pi_{\mathrm{c}} \quad$ price of plant's contracted energy (\$/MWh)

$\pi_{\text {ERM }} \quad$ tariff of the ERM for plant's reallocated energy (\$/MWh)

$\pi_{\mathrm{SPD}} \quad$ price for energy imbalances $(\$ / M W h)$

$E_{\mathrm{c}} \quad$ plant's contracted energy (MWh)

$E_{\mathrm{p}} \quad$ plant's produced energy (MWh)

$E_{\mathrm{r}} \quad$ plant's reallocated energy (MWh)

$\Delta c_{\mathrm{p}} \quad$ variation of the unitary cost for plant's produced energy (\$/MWh)

$\Delta E_{\mathrm{p}} \quad$ variation of the plant's produced energy (MWh)

$\Delta E_{\mathrm{r}} \quad$ variation of the plant's reallocated energy (MWh)

$\Delta E_{\mathrm{s}} \quad$ variation of the plant's scheduled energy ( $\mathrm{MWh}$ )

$k \quad$ percentage of $\Delta E_{\mathrm{s}}$ that is reallocated (\%)

$n \quad$ number of operating units inside the plant

$p \quad$ generated power of each unit inside the plant (MW)

$q \quad$ water discharge of each unit inside the plant $\left(\mathrm{m}^{3} / \mathrm{s}\right)$

$T \quad$ number of time stages

$h_{t} \quad$ duration of period $t(\mathrm{~h})$

Q plant's target discharge $\left(\mathrm{m}^{3} / \mathrm{s}\right)$

$\eta_{\mathrm{eq}} \quad$ equivalent efficiency of the turbine-generator set (\%)

$a_{i} \quad i$ th coefficient of the hydroelectric production function $\left(\mathrm{MW} /\left(\mathrm{m}^{3} / \mathrm{s}\right)\right)$

$h_{l} \quad$ net water head of the plant $(\mathrm{m})$

$k_{\text {eq }}$ equivalent constant of the gravitational acceleration and the specific weight of water $\left(k_{\mathrm{eq}}=9.81 \times 10^{-3}\left[\mathrm{MW} /\left(\left(\mathrm{m}^{3} / \mathrm{s}\right) \mathrm{m}\right)\right]\right)$

$t \quad$ time stage index

$j \quad$ index for subgroups of units

\section{References}

[1] Y.G. Rebours, D.S. Kirschen, M. Trotignon, S. Rossignol, A survey of frecuency and voltage control ancillary services-part II: economic features, IEEE Trans. Power Syst. 22 (1) (2007) 358-366.

[2] J.M. Arroyo, F.D. Galiana, Energy and reserve pricing in security and networkconstrained electricity markets, IEEE Trans. Power Syst. 20 (2)(2005) 634-643.

[3] A.L. Costa, A. Simoes-Costa, Energy and ancillary service dispatch through dynamic optimal power flow, Electr. Power Syst. Res. 77 (8) (2007) 1047-1055.

[4] J.G. González, A.M.S. Roque, F.A. Campos, J. Villar, Connecting the intraday energy and reserve markets by an optimal redispatch, IEEE Trans. Power Syst. 22 (4) (2007) 2220-2231.

[5] K. Tarjei, The nordic approach to market-based provision of ancillary services Energy Policy 35 (7) (2007) 3681-3700.

[6] G. Verbic, F. Gubina, Cost-based models for the power-reserve pricing of frequêncy control, IEEE Trans. Power Syst. 19 (4) (2004) 1853-1858.

[7] T. Sousa, J.A. Jardini, M. Masuda, R.A. de Lima, Spinning reserve service pricing in hydroelectric power plants, in: IEEE/PES Transmission and Distribution Conference \& Exposition, Latin America, 2004, pp. 63-68.

[8] Y. Rebours, D. Kirschen, M. Trotignon, Fundamental design issues in markets for ancillary services, Electricity J. 20 (6) (2007) 26-34.

[9] ONS, Commercial arrangements for ancillary services provided by generators submodule 14.2 (2003) (In Portuguese), Online access from January, 2008, available at: http://www.ons.org.br/procedimentos/modulo_14.aspx. 
[10] R. Billinton, R.N. Allan, Reliability Evaluation of Power Systems, Plenum Press, New York, 1994, ISBN 0-306-45259-6.

[11] UCTE, Load-frequency control and performance, Brussels, Belgium (July 2004), http://www.ucte.org/publications/ophandbook/.

[12] ONS, Generation control in normal operation (2005) (In Portuguese), Online access from February, 2008, available at: http://www.ons.org.br/ procedimentos/modulo_10.aspx.

[13] H. Singh, A. Papalexopoulos, Competitive procurement of ancillary services by an independent system operator, IEEE Trans. Power Syst. 14 (2) (1999) 498-504.

[14] CEPEL, Computational programs (2008) (In Portuguese), Online access from October, 2008, available at: http://www.cepel.br/servicos/descprog.shtm.

[15] CCEE, Commercialization and settlement rules module 1, settlement price for differences (2007) (In Portuguese), Online access from January, 2008, available at: http://www.ccee.org.br/.
[16] CCEE, Commercialization and settlement rules module 4, assured energy (2007) (In Portuguese), Online access from January, 2008, available at: http://www.ccee.org.br/.

[17] ANEEL, Tariffs used to calculate financial compensations and to cover costs in plants are approved by aneel (2007) (In Portuguese), Online access from January, 2008, available at: http://www.aneel.gov.br.

[18] E. Finardi, E. da Silva, Unit commitment of single hydroelectric plant, Electr. Power Syst. Res. 75 (2) (2005) 116-123.

[19] O. Nilsson, D. Sjelvgren, Hydro unit start-up costs and their impact on the short term scheduling strategies of swedish power producers, IEEE Trans. Power Syst. 12 (1) (1997) 38-44.

[20] A.S.A. Encina, S.S. Filho, T. Ohishi, M.A. Cicogna, Unit commitment of hydro dominated systems, Int. J. Emerg. Electr. Power Syst. 9 (4) (2008) $1-17$. 